\title{
A CRESCENTE ESCOLARIZAÇÃO DO AGENTE COMUNITÁRIO DE SAÚDE: UMA INDUÇÃO DO PROCESSO DE TRABALHO?
}

\author{
THE INCREASING SCHOOLING OF THE COMMUNITY HEALTH AGENT: AN INDUCTION OF \\ THE WORK PROCESS?
}

\author{
Roberta Rodrigues de Alencar Mota ${ }^{1}$ \\ Helena Maria Scherlowski Leal David ${ }^{2}$
}

Resumo O agente comunitário de saúde (ACS) é um dos atores profissionais que compõem as equipes da Estratégia Saúde da Família (ESF), sendo sua atuação considerada fundamental para a ampliação e consolidação dessa estratégia. Desde as primeiras experiências locais com ACS em fins dos anos 1970, seu perfil sociodemográfico vem apresentando mudanças. Este artigo tem por objetivo apresentar e discutir o aspecto da escolaridade e da capacitação dos ACS que atuam na Área Programática (AP) 5.2 do município do Rio de Janeiro, articulando trabalho e educação e entendendo o trabalho como um princípio emancipatório. Este estudo foi formulado com base na ideia de triangulação metodológica, aqui alcançada a partir da formulação original de Denzin. Os dados sobre a escolaridade dos ACS foram obtidos mediante questionário autoaplicável individual, respondidos por 301 ACS dos 12 módulos de ESF e seis módulos da Estratégia de Agentes Comunitários de Saúde (EACS) da AP 5.2. A apresentação e a discussão dos dados mostram mudanças no perfil de escolaridade desse trabalhador, concluindo-se que o ACS é um trabalhador que busca alternativas de escolarização e formação profissional. Defende-se a ampliação da escolaridade e o ensino técnico como processo para a consolidação do Sistema Único de Saúde.

Palavras-chave agente comunitário de saúde; escolarização; formação profissional.
Abstract Community health agents (CHA) are among the professional players that make up the Family Health Strategy (FHS) teams, and their performance is considered as critical to the expansion and consolidation of this strategy. Since the first local experiences with CHAs in the late 1970s, their sociodemographic profile has been changing. This article aims to present and discuss the aspect of education and training of the CHAs who work in Program Area (PA) 5.2 of the city of Rio de Janeiro, integrating work and education and understanding the work as an emancipatory principle. This study was formulated based on the methodological triangulation idea, reached here based on the original formulation of Denzin. Data on the CHAs' education were obtained via an individual self-applied questionnaire answered by 301 of the CHAs of the 12 FHS modules and six Community Health Workers Strategy (CHWS) modules of PA 5.2. The presentation and discussion of the data show changes in this worker's educational profile, and it can be concluded that the CHA is a worker who is in search of alternative schooling and vocational training. An expansion of the schooling and technical education is defended as a process to consolidate the Unified Health System.

Keywords community health agent; schooling; vocational training. 


\section{Introdução}

É atual e vigente a discussão das propostas trazidas pela Estratégia Saúde da Família (ESF) e pela Estratégia de Agentes Comunitários de Saúde (EACS) como políticas do Ministério da Saúde (MS) que preveem a reorientação e a reorganização do modelo assistencial no país. Inicialmente concebidos como programas de saúde, desde 1997 a ESF e a EACS passaram a ser prioridades do Plano de Ações e Metas do Ministério da Saúde, sendo temas importantes na discussão sobre políticas públicas de assistência a saúde (Brasil, 1997).

No município do Rio de Janeiro, assim como em outros municípios do território nacional, a ESF ainda se encontra em processo de consolidação e expansão. Desde 2003, o Projeto de Expansão e Consolidação do Saúde da Família (Proesf) tem colocado como um desafio a ampliação da ESF para os grandes centros urbanos, devido à heterogeneidade das condições econômicosociais aí encontradas (Brasil, 2003). O município do Rio de Janeiro enquadra-se nesse contexto, uma metrópole com contrastes sociais e áreas sujeitas a constantes problemas de segurança e ordem pública, e onde, como em outras regiões metropolitanas brasileiras, o cidadão enfrenta dificuldades no acesso aos serviços públicos de saúde.

O agente comunitário de saúde (ACS) é um dos atores profissionais que compõem as equipes da ESF e EACS, com atuação considerada fundamental para a implantação e consolidação dessa estratégia. É um trabalhador que provém das classes populares e que possui características próprias, visto que trabalha e atua na comunidade em que reside. Seu papel nem sempre tem uma definição clara, sendo constantemente utilizados os termos 'mediador' e 'elo de ligação' entre as famílias e o serviço de saúde (Brasil, 2000; Mendonça, 2004; Kluthcovsky e Takayanagui, 2006; Bornstein e Stotz, 2008).

A criação da profissão de agente comunitário de saúde ocorreu recentemente, por meio da lei n. ${ }^{\circ}$ 10.507/02 (Brasil, 2002). Em 2006, foi promulgada a emenda constitucional n. ${ }^{\circ} 51$ (EC 51), que prevê a possibilidade de contratação desse trabalhador através de processo seletivo público (Brasil, 2006a). Posteriormente, a EC 51 foi regulamentada pela lei n. ${ }^{\circ} 11.350 / 06$ (Brasil, 2006b), mas ainda não há garantia efetiva da formalização da contratação nem clareza quanto ao processo de trabalho. Residir na comunidade onde irá atuar, ter concluído o ensino fundamental e haver concluído com aproveitamento o curso de qualificação básica para a formação de agente comunitário de saúde são alguns dos requisitos estabelecidos para ser contratado como ACS (Brasil, 2002). Anteriormente à nova lei, era necessário apenas que o ACS soubesse ler e escrever.

Desde as primeiras experiências locais com ACS em fins dos anos 1970, apoiadas por iniciativas ligadas às pastorais da Igreja Católica, passando 
pela inclusão desse trabalhador em ações programáticas de governos estaduais e municipais, até chegar ao atual processo de mobilização pela profissionalização, o perfil sociodemográfico do ACS vem apresentando mudanças. Nas experiências pioneiras, as exigências de trabalho do ACS, articuladas às motivações que levavam ao desenvolvimento de tais experiências, exigiam um perfil menos técnico e mais voltado para o uso de habilidades relacionais e pedagógicas (Bornstein, 2007). Embora alguns relatos sobre estes projetos já apontassem para o caráter ambíguo do trabalho do ACS, defendia-se, normalmente, um tipo de atuação mediadora que acabava por privilegiar a indicação de mulheres com um perfil de liderança ou mobilização comunitária, pessoas sem escolaridade mínima exigida, o que permitia, inclusive, a inclusão de mulheres analfabetas (David, 2001).

Este perfil vem sofrendo mudanças, em especial no que se refere às competências técnicas e políticas esperadas na atuação do ACS. Ao complexo conjunto de motivações e necessidades sociais, institucionais e pessoais que levam uma pessoa moradora em áreas periféricas a ingressar no ofício de ACS, vem se somando a mobilização coletiva dessa classe pelo reconhecimento do seu trabalho. No que se refere às políticas de formação para o trabalho, definiu-se, nos últimos anos, um processo de certificação por competências baseado em uma escolaridade mínima, numa perspectiva inclusiva de defesa do direito ao acesso à escola por parte de todos os trabalhadores, referendado pelo Referencial Curricular para Curso Técnico de Agente Comunitário de Saúde, proposto pelo MS em 2004 (Brasil, 2004).

Esse curso é oferecido em algumas das 36 escolas que formam a Rede de Escolas Técnicas do Sistema Único de Saúde (RET-SUS) e "visa preparar profissionais para atuar como técnicos de nível médio junto às equipes multiprofissionais que desenvolvem ações de cuidado e proteção à saúde de indivíduos e grupos sociais, em domicílios e coletividades" (Brasil, 2004, p. 16). A RET-SUS é uma estratégia de articulação, troca de experiências, debates coletivos e construção de conhecimento em Educação Profissional em Saúde. Trata-se de uma rede governamental criada para fortalecer a formação do pessoal de nível médio que atua na área da saúde.

Nessa diretriz estabelecida pelo MS (Brasil, 2004), a relevância do trabalho do ACS no contexto de mudanças das práticas de saúde e o papel social deste trabalhador junto à população constituem a necessidade de sua formação, realizada em nível técnico, e reafirma a intenção do governo de associar educação profissional à elevação de escolaridade.

O acesso ao curso técnico de agente comunitário de saúde ocorre da seguinte forma (Brasil, 2004): a) etapa formativa I - formação inicial: acesso a todos os agentes comunitários de saúde inseridos no Sistema Único de Saúde (SUS), independentemente da escolarização; b) etapa formativa II concluintes da etapa formativa I, com certificado de conclusão ou atestado 
de realização concomitante do ensino fundamental; c) etapa formativa III concluintes das etapas formativas I e II, com certificado de conclusão ou atestado de realização concomitante do ensino médio.

Apesar dessa iniciativa, na prática ainda não se observa empenho dos governos locais em incentivar a formação técnica do ACS. No município do Rio de Janeiro, o curso técnico para essa função é organizado pela Escola de Formação Técnica em Saúde Enfermeira Izabel dos Santos (Etis), vinculada à Secretaria de Estado de Saúde e Defesa Civil. É dividido em três módulos, totalizando uma carga horária de 1.200 horas. Desde 2005, poucos ACS do município participaram do primeiro módulo do curso, de 400 horas, e o segundo só poderá ter início quando todos os ACS tiverem concluído a primeira etapa. Até o momento da finalização deste artigo, não houve avanço na continuidade desse curso.

Esse processo de profissionalização tem se dado num campo de disputas de interesses diversos, em que a correlação de forças se apresenta de modo diferenciado, a depender da região do país e dos arranjos institucionais e políticos em curso (Morosini, Corbo e Guimarães, 2007). Mais recentemente, é inegável que algumas conquistas estejam relacionadas à mobilização coletiva e à organização de entidades de representação estadual e nacional por parte dos ACS, que compõem um contingente de mais de 200 mil trabalhadores no país.

É preciso contextualizar este perfil, também, no que tange ao processo de ampliação geral da escolaridade do adulto brasileiro, ocorrida nos últimos anos. O Brasil está passando por uma transição da escolaridade da população, como consequência também de uma transição demográfica, visto que a proporção de jovens com menos de 20 anos de idade vem diminuindo (Rigotti, 2001). Acompanhando essa transição, já se vislumbra uma tendência à diminuição da demanda escolar, o que favoreceria sobremaneira o aumento de recursos para a tão necessária melhoria na qualidade do ensino.

Há 30 anos, por ocasião da publicação da Carta de Alma-Ata, documento que se constituiu num marco para o surgimento do ACS, não se poderia prever que ser agente comunitário de saúde se constituiria em uma profissão. Diferentemente de outros países, como o México e o Peru, nos quais os ACS ainda se vinculam a iniciativas locais ou estaduais e são trabalhadores voluntários (embora possam existir outras formas de compensação para este ofício que não o salário ou um contrato formal de trabalho), o processo de desenho e consolidação do SUS passou a incluir este profissional, que não encontra possibilidade de atuação fora da esfera pública de saúde.

Esse processo de profissionalização não significa que estejam superadas as concepções ideologizadas e paternalistas a respeito do ACS, que defendem o retorno ao voluntariado, e as tensões decorrentes da presença de um trabalhador de perfil profissional ambíguo e em processo de definição, 
oriundo das classes populares, como parte de uma equipe de ESF constituída prioritariamente por profissionais médicos, enfermeiros e odontólogos. No entanto, reconhece-se que pode haver também um sentido emancipatório, de valorização pessoal e social, neste processo de luta pelo reconhecimento profissional, e no próprio trabalho como ACS. Interessa, portanto, mapear o processo de escolarização formal deste trabalhador, atualizando seu perfil e buscando compreender como este processo se articula aos pressupostos de mudança no modelo assistencial apontados pelas estratégias em curso.

Este artigo tem por objetivo apresentar e discutir o perfil de escolaridade e de capacitação para o trabalho de agentes comunitários de saúde do município do Rio de Janeiro que atuam na Área Programática (AP) 5.2 do município.

Esta discussão busca estabelecer uma interface entre o mundo do trabalho e a educação, partindo do pressuposto que, em um mundo de economia globalizada, palco de rápidas transformações, o trabalho constitui-se ainda na principal forma de inclusão e reconhecimento social. Na organização do texto, descrevem-se, primeiramente, a abordagem metodológica adotada, seguindo-se alguns apontamentos teórico-conceituais sobre o trabalho como princípio educativo e emancipatório. A seguir, traça-se um breve histórico da incorporação de ACS ao trabalho em saúde na AP 5.2 do Rio de Janeiro. A apresentação e a discussão dos dados mostram que as mudanças no perfil de escolaridade desse trabalhador são desenvolvidas à luz dos conceitos apresentados. Defende-se o avanço do processo de profissionalização para dar oportunidade a este trabalhador de ampliação da escolaridade e de acesso a uma formação técnica capaz de desenvolver as competências para sua atuação dentro de um modelo de saúde democrático e de acesso universal.

\section{Metodologia}

O projeto integrado que deu origem a este estudo foi formulado com base na ideia de triangulação metodológica, aqui entendida a partir da formulação original de Denzin (1973), aproximando-se do conceito de combinação de métodos, na intencionalidade de ampliar o olhar sobre um determinado fenômeno, por meio de técnicas diversas e também de uma postura colaborativa, do ponto de vista epistemológico, rompendo com a ideia de saberes hierarquizados. Não se trata apenas de prever um conjunto de técnicas para a coleta e análise de dados, senão também de avançar na construção de conhecimentos interdisciplinares acerca de uma dada realidade.

À medida que a pesquisa avançou ao longo dos anos de 2008 e 2009, foram realizadas oficinas e entrevistas em grupos focais, interpondo-se abordagens específicas, de caráter quantitativo, descritivos e transversais, para a obtenção de dados que permitissem aprofundar e clarear questões 
que vinham sendo desveladas pela análise qualitativa das narrativas, baseada nas perspectivas hermenêutico-críticas e de análise de conteúdo.

Os dados sobre a escolaridade dos ACS foram obtidos a partir de um questionário autoaplicável individual, distribuído entre os 12 módulos de ESF e seis módulos de EACS da AP 5.2, solicitando-se o preenchimento da situação de escolaridade por todos os componentes das equipes. As variáveis indagadas foram: idade, sexo, tempo de atuação como ACS, escolaridade formal no início do trabalho como ACS, escolaridade atual e especificação do curso, caso estivesse estudando no momento.

Do universo de 316 ACS, foram analisados 301 questionários respondidos, que correspondem a 95\% da população de ACS da área estudada. As perdas se referem ao não preenchimento do questionário dos que, na ocasião da pesquisa, se encontravam em férias ou afastados do trabalho devido a licenças médica ou de maternidade.

Os dados foram tabulados em frequências simples e relativas, e a lista de cursos especificados gerou dois grupos: um relativo aos cursos das áreas da saúde, e outro agrupando os cursos de outras áreas. Esta opção se justifica pelo fato de terem sido mais frequentes os cursos das áreas da saúde, e pela intenção de buscar identificar em que medida os ACS permanecem vinculados a esta área quando comparada com as demais áreas.

O estudo foi submetido à apreciação pelo Comitê de Ética em Pesquisa com Seres Humanos (CEPs) da Secretaria Municipal de Saúde (SMS-RJ), obtendo registro de aprovação n. ${ }^{\circ}$ 33A/2008, sendo atendidas todas as normas da resolução n. ${ }^{\circ}$ 196/96 do Conselho Nacional em Saúde.

\section{O trabalho como princípio educativo}

O significado da palavra escola, em grego, é 'lugar do ócio'. Ou seja, na pólis grega, só as classes ociosas tinham acesso às escolas. A classe dominante tinha acesso a uma educação escolar, enquanto as classes trabalhadoras tinham acesso, quando muito, a algum treinamento de caráter instrumental. A educação do povo, em geral, se dava no próprio processo de trabalho; aprendia-se na ação, transformando a natureza e a realidade. É reconhecido, portanto, desde a antiguidade, o princípio educativo do trabalho (Saviani, 2010).

Na modernidade, a perspectiva do trabalho como princípio educativo é bastante desenvolvida por Gaudêncio Frigotto, que em suas obras desenvolve a articulação entre trabalho e educação. Para Frigotto, o princípio educativo do trabalho advém da

sua especificidade de ser uma atividade necessária desde sempre a todos os seres humanos. O trabalho constitui-se, por ser elemento criador da vida humana, num 
dever e num direito. Um dever a ser aprendido, socializado desde a infância. Trata-se de apreender que o ser humano enquanto ser da natureza necessita elaborar a natureza, transformá-la, pelo trabalho, em bens úteis para satisfazer as suas necessidades vitais, biológicas, sociais, culturais, etc. Mas é também um direito, pois é por ele que pode recriar, reproduzir permanentemente sua existência humana (Frigotto, 2001, p. 74).

Frigotto realiza uma crítica ao projeto de Educação Profissional do governo federal, considerando-a subordinada ao ideário do mercado e do capital e de um modelo de desenvolvimento concentrador de renda, resultando em exclusão e desemprego, vinculando-se a uma perspectiva de acomodação do trabalhador, conformando, desse modo, um cidadão mínimo, que pensa e (re)age minimamente. Essa formação é focada numa ótica individualista, que sequer habilita o cidadão e lhe dá o direito a uma profissão ou a um emprego, tornando-o mão de obra disponível no mercado de trabalho sob os domínios do capital (Frigotto, 2001).

Ciavatta traz reflexões importantes para pensarmos em como o trabalho pode se constituir num princípio educativo. O trabalho como ação possibilita mudanças, mas pode ser, ou não, um princípio educativo, dependendo das condições em que se desenvolve (Ciavatta, 2005). O trabalho pode se constituir em um princípio educativo negativo na medida em que pode provocar alienação, desqualificação e desigualdades, se totalmente condicionado pela educação que conduz à subordinação ao capital, disciplina e produtividade (Ciavatta, 2005).

Esta autora observa que, em contraponto, a produção da existência humana e a aquisição de consciência se dão através do trabalho, sendo este uma atividade fundamental, em que o ser humano se cria, se renova e humaniza. Discorre também sobre a necessidade de se pensar o trabalho em outro contexto social, em que o trabalhador produza para si, em que o produto do trabalho coletivo seja distribuído de forma igualitária, constituindo uma nova relação social.

Abordando a questão das relações entre trabalho, história e saberes, Yves Schwartz (1996) reconhece que toda vida humana é atravessada de história. Neste contexto, o autor ainda discursa que o trabalho também é atravessado pela história e o trabalhador faz história em toda atividade laboral. Schwartz cita uma expressão relevante de Paulo Freire, acerca de a história estar sempre 'inacabada', significando que a história se (re)escreve continuamente, assim como o saber se recria. Schwartz também cita Frigotto, que afirma o homem como ser social que se cria e recria pelo trabalho.

O inacabamento da história e do homem é um tema central na pedagogia crítica de Paulo Freire (2005), que reconhece os homens como seres que 'estão sendo', como seres da busca, inacabados, inconclusos, possuindo uma 
vocação ontológica de 'ser mais'. O homem tem plena consciência de sua inconclusão, se sabe inacabado e, cada um, dentro de suas habilidades e potencialidades, encontra-se nesse processo de busca, de crescimento, de emancipação.

Escrever sobre emancipação numa sociedade ainda tão 'opressora', remetendo novamente a Freire, é, no mínimo, desafiador. O que se defrontará também com inúmeras contradições e contrastes. As contradições que o capitalismo impõe fazem com que o trabalho seja um campo contraditório e ambíguo. A subjetividade e individualidade humana estão fundidas, na origem do que se chama de metabolismo social do capital (Maciel, 2006).

Na perspectiva de crítica ao modo de produção capitalista claro está que não estamos caminhando para a mudança na direção de uma ordem social mais justa, já que o capital se reconfigura, e não se percebe mudanças efetivas em sua lógica. Na análise de Stotz:

O capitalismo ainda é aquele analisado por Marx e Engels no Manifesto do Partido Comunista de 1848, caracterizado pela tendência a se expandir além da capacidade de consumo da sociedade. A crise é uma consequência inevitável desta tendência. E, com ela, vem abaixo também a fantasia de que o mercado possa se autoregular. Então, melhor entregar os anéis do que os dedos - pensam os capitalistas: afinal, uma recessão econômica, com a destruição de capitais, de postos de trabalho e a diminuição de renda, é melhor do que uma outra depressão mundial capaz de conduzir os estados-nações ao protecionismo e, portanto, à limitação do movimento dos capitais financeiros pelo mundo em busca de superlucros (Stotz, 2009, p. 10).

Em uma análise da imposição do econômico sobre o humano, Gorz traz sua crítica sobre a racionalização econômica do trabalho. O autor afirma que

a racionalização econômica do trabalho venceu, portanto, a resistência das antigas idéias de liberdade e de autonomias existenciais. Fez nascer o indivíduo que, alienado em seu trabalho, também o será, obrigatoriamente, em seu consumo e, finalmente, em suas necessidades (Gorz, 2007, p. 31).

O trabalhador alienado, nesse aspecto, não possui potencial para o rompimento com a lógica do capitalismo.

A emancipação está subordinada à superação do que Freire chama de 'situações-limites', barreiras que impedem o homem de 'ser mais'. Para este autor, homens e mulheres, como seres conscientes, sabem de sua liberdade ou de seus condicionamentos. Sendo assim, constantemente encontram em sua vida, pessoal e social, obstáculos que precisam ser ultrapassados, superados. Esses obstáculos Freire chamou de situações-limites, que são realidades objetivas e que provocam necessidades nos indivíduos. Para a superação é 
preciso 'a ação' dos homens sobre a realidade concreta em que se dão as 'situações-limites' (Freire, 2005, p. 105). Entretanto, nem sempre os homens assumem uma postura de superação frente a essas situações: podem percebê-las como obstáculos que 'não podem' transpor ou podem simplesmente encará-los como algo que 'não querem' transpor. É a partir da superação das situações-limites que o homem passa a vislumbrar o 'inédito viável', que discutiremos mais adiante. Será que, neste contexto, podemos considerar o trabalho do ACS como uma 'situação-limite'? E essa situação limite o levaria a vislumbrar um 'inédito viável'?

Nessa lógica, a possibilidade de atuar como ACS representa, para muitos, uma possibilidade de ingresso ou de reingresso no mercado de trabalho (Silva e Dalmaso, 2002). Através da ampliação da escolaridade, a busca de outros espaços, de alternativas, se constituiria num inédito viável para o ACS? Mesmo nas classes populares, nos seus modos de viver, há uma forte tendência à reprodução da lógica individualista e consumista. No seu imaginário, a escolarização pode representar uma saída, uma possibilidade de mudança.

É nesse sentido que se pode perceber o caminho atualmente trilhado pelos ACS: um movimento transformador, de (re)construção, (re)inclusão e, sobretudo, de esperança.

\section{Histórico da atuação dos ACS na AP 5.2}

A primeira experiência em Saúde da Família (SF) na AP 5.2, campo desse estudo, ocorreu em 1999, com um projeto piloto de conversão de Unidade Básica de Saúde (UBS) tradicional em ESF, na comunidade Vilar Carioca, localizada no bairro de Inhoaíba, zona oeste do Município. Nessa ocasião, foram implantadas inicialmente três equipes, ainda como uma experiência isolada na ESF (Moura, 2009). Em 2002, a então Coordenação de Saúde da Comunidade da Secretaria Municipal de Saúde (CSC-SMS) do Rio de Janeiro elaborou o planejamento da expansão da ESF no município, iniciada em 2003.

Neste processo de expansão houve a priorização da ampliação desse serviço de atenção básica para áreas consideradas vazios assistenciais. Nesse mesmo ano foram implantadas na área nove equipes de EACS em imóveis alugados pela Prefeitura. Como componente histórico, vale destacar que essa modalidade de EACS foi denominada pela CSC, à época, Programa de Agentes Comunitários de Saúde (Pacs) Adaptado (Moura, 2009), visto que não foram alocados em UBS tradicionais como preconizado pelo Ministério da Saúde, e não estava colocada a perspectiva de estratégia transitória para a ESF. Além disso, na época também havia uma dificuldade de contratação de médicos que possibilitasse o início dessa expansão já com a ESF. 
A partir de 2004, gradativamente foram implantadas novas equipes de ESF. Duas experiências bem-sucedidas da EACS possibilitaram a conversão de mais duas UBS da área em ESF, reafirmando o caráter substitutivo dessa estratégia.

A ESF ainda se encontra em processo de consolidação e expansão no município do Rio de Janeiro. Dentro desse universo expressivo do ACS e tendo como base o projeto mais amplo sobre esse trabalhador, vislumbramos a possibilidade de estudar o perfil de escolaridade dos ACS da AP 5.2, como forma de compreender a trajetória de vida e trabalho deste ator singular no contexto do sistema de saúde.

A área escolhida compreende os bairros de Campo Grande, Guaratiba, Barra de Guaratiba, Pedra de Guaratiba, Santíssimo, Vasconcelos, Cosmos e Inhoaíba, situados na zona oeste e distante aproximadamente 52 quilômetros do centro da cidade. Esta área abrange também duas regiões administrativas (RA) da cidade, as XVIII e XXVI RA. De acordo com dados do site do Instituto Pereira Passos (IPP), a AP 5.2 ocupa uma área de 305,92 quilômetros quadrados, o que corresponde a $24,98 \%$ do território do município e $34,59 \%$ do território da zona oeste da cidade. Seus limites de extensão são o município de Nova Iguaçu (ao norte), a AP 5.1 (a leste), a AP 5.3 e Baía de Sepetiba (a oeste) e a AP 4.0 e o Oceano Atlântico (ao sul). O IPP estima a população total desta área em 804.985 habitantes, apresentando um número de habitantes muito próximo ao de alguns municípios considerados dentre os mais populosos do estado em estimativa populacional para 2009, divulgada pelo Instituto Brasileiro de Geografia e Estatística (IBGE) em 14 de agosto de 2009, como Duque de Caxias (872.762) e Nova Iguaçu (865.089).

Atualmente existem 42 equipes de ESF e sete equipes de EACS na AP 5.2, o que contabiliza uma força de trabalho de 316 ACS. De acordo com os dados do Sistema de Informação da Atenção Básica (Siab) de dezembro de 2009, na AP 5.2 existem aproximadamente 42.385 famílias e 169.540 cidadãos acompanhados por equipes de ESF e EACS.

\section{Resultados e discussão}

Com relação ao sexo, 82\% da população de ACS da AP 5.2 são constituídos de mulheres (Tabela 1). O trabalho de ACS, não só no Rio de Janeiro, é um trabalho reconhecidamente associado ao trabalho doméstico feminino, que possui uma inclinação historicamente reconhecida para o cuidado em saúde. Nesse sentido, tomando por base o relato de David (2001), há expressiva predominância de mulheres no trabalho de ACS em todo o país. 
Tabela 1

\begin{tabular}{|c|c|c|c|c|c|c|}
\hline \multicolumn{7}{|c|}{ Perfil geral de idade e sexo } \\
\hline Faixa etária & Homens (54) & $\%$ & Mulheres (247) & $\%$ & Total & $\%$ \\
\hline$\leq 20$ & - & - & 5 & 1,6 & 5 & 1,6 \\
\hline $21-25$ & 4 & 1,3 & 19 & 6,3 & 23 & 7,6 \\
\hline $26-30$ & 15 & 5 & 59 & 20 & 64 & 25 \\
\hline $31-35$ & 9 & 3 & 54 & 18 & 63 & 21 \\
\hline $36-40$ & 10 & 3,3 & 40 & 13,3 & 50 & 16,6 \\
\hline $41-45$ & 7 & 2,3 & 32 & 10,6 & 39 & 12,9 \\
\hline $46-50$ & 2 & 0,6 & 20 & 6,6 & 22 & 7,2 \\
\hline $51-55$ & 4 & 1,3 & 8 & 2,7 & 12 & 4 \\
\hline $56-60$ & 2 & 0,6 & 4 & 1,3 & 6 & 1,9 \\
\hline$\geq 61$ & 1 & 0,3 & 2 & 0,6 & 3 & 0,9 \\
\hline Não informada & - & - & 4 & 1,3 & 4 & 1,3 \\
\hline
\end{tabular}

Fonte: As autoras.

A incorporação de um eixo de análise do trabalho do ACS numa perspectiva de gênero partiu do pressuposto de que o trabalho feminino, nas sociedades capitalistas, tende a ser desvalorizado. Isto se aplica, em especial, ao trabalho doméstico, ou a todas as modalidades de trabalho nas quais o cuidado e a relação interpessoal são características marcantes. Estas formas de trabalho não são reconhecidas na sua essencialidade para a produção e a reprodução da vida da sociedade (Barbosa, 2009):

A respeito desta questão, podemos sinalizar que a solidariedade pelo próximo, pela comunidade, é, em nossa cultura, uma qualidade moral associada ao feminino, ao sentimento materno, ao cuidado do outro. Neste sentido, podemos supor que o trabalho de ACS, majoritariamente realizado por mulheres, está fortemente calcado na promoção destes sentimentos/valores, que, em muitos sentidos, levam esses/as trabalhadores/as a permanecerem no emprego, mesmo em condições tão desvantajosas e precárias (Barbosa, 2009, p. 42).

Em todas as regiões do país a maioria dos trabalhadores ACS é mulher, e as profissões, associadas ao papel feminino, geralmente apresentam questões de precarização e instabilidade. Apesar disso, o problema do desemprego atualmente pode influenciar para que os homens busquem alternativas até mesmo em áreas de atuação predominantemente femininas. 
Por outro lado, trabalhar próximo à sua residência e poder controlar e acompanhar o cotidiano dos filhos, sobretudo quando em idade escolar, pode representar para essas mulheres uma vantagem que se sobrepõe aos baixos salários e à precarização.

Apesar do contingente de ACS do sexo masculino da AP 5.2 ainda ser de apenas $18 \%$, já percebemos uma mudança no perfil de gênero geralmente encontrado entre as equipes de ACS, com a inserção dos homens em um campo de atuação antes restrito a mulheres. Isso traz algumas mudanças, percebidas a partir das narrativas durante as oficinas e os grupos focais: os ACS do sexo masculino tendem a estar na liderança da representação da categoria profissional e dos processos de negociação para o avanço da profissionalização; houve ainda a percepção de que o ACS homem tende a ser visto como 'um profissional', enquanto a ACS mulher é percebida pela comunidade como 'uma amiga'.

Em relação à idade, a faixa etária predominante é de adultos jovens, já que $63 \%$ dos ACS têm idade entre 26 e 40 anos. Em comparação aos achados no estudo de David (2001), realizado no município de Petrópolis, localizado na região serrana do Estado do Rio de Janeiro, encontramos uma mudança no perfil de idade e de sexo entre os ACS. À época do estudo, as equipes de ACS de Petrópolis eram constituídas exclusivamente de mulheres e com faixa etária mais elevada que a predominante na AP 5.2, estando elas na faixa dos 35 aos 45 anos de idade.

As mudanças que ocorreram durante o processo de profissionalização e de ampliação da presença de ACS em áreas urbanas são os fatores que, ao nosso ver, colaboraram para que o perfil etário passasse a incluir não apenas, e principalmente, mulheres acima dos 30 anos, atraindo os mais jovens para o mercado de trabalho aberto durante os processos seletivos.

Aproximadamente $50 \%$ dos ACS estão atuando há menos de dois anos na profissão (Tabela 2). Nesse aspecto, devemos atentar para o fato de que três unidades de ESF foram inauguradas há menos de dois anos, justificando, em parte, o pouco tempo de atuação desse ACS. A ESF existe na área estudada há dez anos e o início da expansão em todo o município ocorreu há sete anos. Apesar de boa parte dos ACS atuar há menos de dois anos, o que também demonstra uma rotatividade de contratação, 36,3\% permanecem na função entre quatro e sete anos. As dificuldades de inserção no mercado formal de trabalho podem, em muito, contribuir para a permanência do ACS nessa função. 
Tabela 2

\begin{tabular}{lcccccc}
\hline \multicolumn{2}{l}{ Tempo de atuação como ACS, por sexo } & & & & \\
\hline $\begin{array}{l}\text { Tempo de atuação } \\
\text { como ACS }\end{array}$ & Homens & $\%$ & Mulheres & $\%$ & Total absoluto & Total \% \\
\hline & & & & & & \\
\hline \\
< de 1 ano & 10 & 3,3 & 70 & 23,3 & 80 & 26,6 \\
1 a 2 anos & 12 & 4 & 58 & 19,3 & 70 & 23,3 \\
2 a 3 anos & 3 & 1 & 11 & 3,7 & 14 & 4,7 \\
3 a 4 anos & 1 & 0,3 & 10 & 3,3 & 11 & 3,6 \\
4 a 5 anos & 6 & 2 & 39 & 13 & 45 & 15 \\
5 a 6 anos & 11 & 3,7 & 20 & 6,6 & 31 & 10,3 \\
6 a 7 anos & 9 & 3 & 24 & 8 & 33 & 11 \\
7 a 8 anos & 1 & 0,3 & 6 & 2 & 7 & 2,3 \\
8 a 9 anos & 1 & 0,3 & 5 & 1,6 & 6 & 1,9 \\
9 a 10 anos & - & - & 1 & 0,3 & 1 & 0,3 \\
Não informada & - & - & 3 & 1 & 3 & 1 \\
& & & & & & \\
\hline
\end{tabular}

Fonte: As autoras.

Realizando uma comparação entre a escolaridade desses ACS ao início da profissão e sua escolaridade atual, encontramos uma considerável elevação do grau de instrução. Atualmente, apenas 2,7\% dos ACS possuem nível fundamental, onde antes se observava 9,6\%. O nível de instrução predominante dentre a maioria desses trabalhadores é o nível médio. Observamos que, mesmo com a elevação da escolaridade, muitos permanecem na profissão.

Atualmente, $26 \%$ dos ACS em foco continuam estudando ou, em sua maioria, voltaram a estudar após se iniciar nesse trabalho. Destes, $46 \%$ ingressaram no ensino superior, $17 \%$ no ensino médio e $24 \%$ estão cursando ensino técnico. Dessa última categoria, $50 \%$ estão realizando curso técnico em enfermagem; $11 \%$ estão realizando outros cursos de nível médio; $40 \%$ do total optaram por profissões da área da saúde e $28 \%$, pela área de humanas (Tabela 3). Entendemos que os cursos de ensino médio e técnico se configuram igualmente como nível médio de ensino, porém optamos por deixá-los em separado, já que o ensino técnico confere algum grau de diferenciação a esse trabalhador com relação à formação específica e profissionalização. 
Tabela 3

\begin{tabular}{lcccc}
\hline \multicolumn{4}{l}{ Comparação do perfil de escolaridade dos ACS ao início do trabalho e atual } \\
\hline Nível de formação & $\begin{array}{l}\text { Escolaridade ao } \\
\text { início do trabalho }\end{array}$ & $\%$ & Escolaridade atual & $\%$ \\
\hline Fundamental incompleto & 1 & 0,3 & - & - \\
Fundamental & 28 & 9,3 & 8 & 2,7 \\
Médio incompleto & 23 & 7,7 & 23 & 7,7 \\
Médio & 210 & 69,8 & 164 & 54,4 \\
Técnico incompleto & - & - & 19 & 6,3 \\
Técnico & 4 & 1,3 & 12 & 4 \\
Superior incompleto & 22 & 7,3 & 54 & 77,9 \\
Superior & 13 & 4,3 & 21 & 7 \\
\end{tabular}

Fonte: As autoras.

Verificamos que houve ampliação em todas as faixas de escolaridade e parece haver um desejo de continuar na área da saúde, que ainda é uma área de boa empregabilidade. Além disso, ao se tornar parte integrante da equipe de Saúde da Família, o ACS passa a ter acesso a um saber técnico-científico, através de treinamentos e da convivência com outros profissionais da equipe. O ACS é um cidadão pertencente à comunidade que passa a integrar as equipes de saúde, sem trazer qualquer bagagem cultural ou técnica pertinentes a esta área (Bachilli, Scavassa e Spiri, 2008). Essa nova experiência de trabalho, de informações, pode contribuir para que busquem alternativas de profissionalização.

Em recente estudo sobre a avaliação da implantação da ESF em grandes centros urbanos, verificou-se, mediante análise do perfil dos ACS pertencentes a essas equipes, que a maioria desses trabalhadores possuía escolaridade alta em relação às exigências para o cargo fixadas pelo MS à época: saber ler e escrever (Brasil, 1997; Mendonça, 2004). A maior parte dos ACS, mais de $60 \%$ da população estudada, possuía ensino médio completo.

Os cursos de nível técnico que os ACS estão realizando são: técnico em administração, técnico em edificações, técnico em enfermagem, técnico em estética, técnico em informática, técnico em mecânica industrial, técnico em radiologia e técnico em segurança do trabalho.

Dentre as opções de curso de nível superior realizado atualmente pelos ACS estão: administração de empresas, arquitetura, biotecnologia, ciências contábeis, direito, educação física, enfermagem, geografia, gestão ambiental, letras, logística, matemática, nutrição, pedagogia, petróleo e gás, psicologia, publicidade, serviço social, tecnologia em processamento de dados, turismo e veterinária. 
Os resultados levam à reflexão acerca dos motivos que levaram esse profissional a procurar novas alternativas de crescimento profissional e trazem à tona alguns questionamentos: a profissão de ACS seria uma alternativa temporária e oportuna ao desemprego, problema vigente em todo o país? Ao mesmo tempo, o que, no processo de trabalho como ACS, o motiva a buscar o seu crescimento profissional e pessoal?

Esses questionamentos abrem espaço a novas reflexões. A possibilidade de atuar como ACS representa, para muitos, uma possibilidade de ingresso ou de reingresso no mercado de trabalho (Silva e Dalmaso, 2002). Contudo, se for considerada como uma profissão de passagem, pode não garantir efetivamente a realização de um vínculo com as famílias e a comunidade. A formação desse vínculo é a garantia de que o agente realmente terá acesso à população e, portanto, poderá desenvolver as suas atribuições.

O ACS é um profissional proveniente das camadas populares e, como tal, almeja melhores condições de vida e de trabalho. Entretanto, escolarização não é garantia dessas melhorias, mas ainda assim tem um valor importante e é socialmente reconhecida para a ascensão social e profissional.

Ingressar nessa profissão possibilita o acesso a um conhecimento, um saber novo, através das capacitações para o trabalho. Participar de uma equipe multiprofissional o aproxima a novas profissões e promove uma identificação com a área da saúde.

Os ACS buscam uma alternativa de vida ao retomar os estudos. Essa projeção idealizada e a ampliação de sua escolaridade podem não significar, entretanto, seu afastamento da área da saúde, que continua sendo preferencial. A partir de alguns relatos, durante as oficinas, pudemos ainda inferir que muitos ACS objetivam crescer na ESF, porém em outra função.

O interesse em ampliar conhecimentos e crescer como indivíduo é visível em seus relatos. A maioria dos entrevistados estava realizando ou já tinha realizado algum curso na área da saúde. Essa busca por uma formação técnica, todavia, denota uma contradição no que é característico do ACS: o saber popular em saúde. Segundo Nunes et al. (2002), o pertencimento a uma equipe de saúde e a formação que eles recebem em serviço "lhes dá um sentimento orgulhoso de diferenciarem o seu conhecimento em relação ao conhecimento popular, o que lhes confere prestígio social" (Nunes et al., 2002, p. 1.641). Nesse sentido, corroboramos com Junges, Mazari e Selli (2008), que afirmam ser necessário conscientizar o ACS sobre o valor do seu conhecimento genuíno, adquirido justamente pela sua origem da comunidade.

Estudar não se configura uma novidade para os ACS desse estudo. Em comum todos têm o pertencimento às classes populares e o fato de, em muitos momentos de sua trajetória pessoal, se sentirem desprovidos de condições para avançar na escolaridade e ir em busca de seus sonhos. O trabalho, nesse 
caso, os aproximou de oportunidades de bolsas de estudo em cursos universitários, em cursos de nível técnico e de alguns cursos profissionalizantes gratuitos.

Vale ainda lembrar que, em todos os campos de atuação do SUS, especialmente no âmbito da ESF, também percebemos um sentido emancipatório no compromisso que é exigido a todos os profissionais de saúde, pelas próprias exigências éticas e políticas de se trabalhar num sistema universal, equânime e integral. Trabalhar numa perspectiva de mudança de lógica de modelo de atenção à saúde exige um trabalhador participativo, crítico, ativo na condução dessa mudança.

\section{Conclusão}

Os agentes comunitários de saúde têm sido objeto de muitos estudos na produção científica recente na área da Atenção Básica. Este estudo procurou abordar uma questão do perfil desse profissional ainda pouco estudada: a escolarização.

Verificamos na AP 5.2 uma ampliação significativa em todas as faixas de escolaridade e parece haver um desejo deste trabalhador de mudar de função, porém permanecendo na área da saúde.

A nova proposta de elevação da escolaridade do ACS, do referencial curricular de 2004, traz no seu bojo uma exigência que não está inscrita nos requisitos exigidos para seu desempenho, que é a conclusão do ensino médio. Além de constituir um elemento indutor da política de formação técnica dos ACS (Morosini, 2009), essa formação é justificada por quatro argumentos constantes do documento: a política de educação profissional para o setor saúde, a importância do ACS na mudança do modelo de atenção, seu papel social e seu perfil de escolaridade. Em contrapartida, serão promovidos a profissionalização e o acesso a um conhecimento técnico-científico que indiscutivelmente contribuirão positivamente para sua prática. Mas esse investimento não resultará na ampliação de um horizonte profissional, já que ele 'continuará sendo' ACS, devido à inexistência de um plano de carreira para esse trabalhador.

Alguns elementos que permeiam o conteúdo das capacitações caracterizam a formação predominante dos ACS como uma qualificação denominada nível básico da educação profissional, o que, portanto, não lhe confere habilitação (Morosini, 2009).

Consideramos que a lei n. ${ }^{\circ} 11.350 / 06$ deixou uma lacuna nesse sentido, mesmo sendo criada após o referencial curricular de 2004, pois reproduz os mesmos requisitos exigidos na lei n. ${ }^{\circ}$ 10.507/02, que criou a profissão de ACS, com relação à formação desse trabalhador: a conclusão de um curso introdutório de formação inicial e continuada e a conclusão do ensino fundamental. 
Entendemos que o incentivo à profissionalização desse trabalhador, instrumentalizando-o tecnicamente para o trabalho, poderá promover uma alteração positiva do perfil desse trabalhador, através da elevação da escolaridade.

O ACS tem um caráter singular por ser um profissional exclusivo do SUS. Deve-se ressaltar também a importância e o potencial transformador desse agente na mudança de modelo de atenção. A falta de investimentos na sua qualificação contribui, sobremaneira, para perpetuar sua baixa remuneração. E até o momento, o município do Rio de Janeiro, assim como a grande maioria dos municípios brasileiros, ainda não desenvolveu, de fato, uma estratégia para incentivar a formação técnica dos ACS.

Devemos pensar no ACS não como alguém que está reproduzindo um modelo de relação de trabalho. Ele traz, como membro das classes populares, a ideia do inédito viável, da superação de limites até então intransponíveis, a possibilidade, mesmo que com percalços no caminho, de uma mudança.

A garantia dessa mudança só será possível com uma ordem social mais justa, a partir de um movimento de luta coletivo, rompendo com alguns preceitos arraigados em nossa sociedade capitalista. Permanecer como ACS, ou garantir que algumas pessoas permaneçam e cumpram com a proposta da ESF, depende principalmente do reconhecimento técnico desse trabalhador.

\section{Nota do Editor}

Este artigo origina-se da dissertação de mestrado Agentes comunitários de saúde: trabalho e formação profissional numa perspectiva emancipatória, do Programa de Pós-Graduação em Enfermagem da Universidade do Estado do Rio de Janeiro, que integra a pesquisa "Abordagem interdisciplinar das novas relações e processo de trabalho em saúde: o caso dos agentes comunitários de saúde", financiada pela Fundação de Amparo à Pesquisa Carlos Chagas do Estado do Rio de Janeiro (Faperj) por meio do Edital Prioridade Rio 2007. 


\section{Notas}

1 Enfermeira da Secretaria Municipal de Saúde e Defesa Civil do município do Rio de Janeiro (SMSDC-RJ), Rio de Janeiro, Brasil. Mestre em Enfermagem pela Universidade do Estado do Rio de Janeiro (Uerj). <robertarodriguesmota@yahoo.com.br> Correspondência: Rua Cabo Moisés de Oliveira, 11, Campo Grande, Rio de Janeiro, RJ, CEP 23.080-250.

2 Professora adjunta da Universidade do Estado do Rio de Janeiro (Uerj), Rio de Janeiro, Brasil. Doutora em Saúde Pública pela Escola Nacional de Saúde Pública Sergio Arouca, Fundação Oswaldo Cruz (Ensp/Fiocruz). <helena.david@oi.com.br>

\section{Referências}

BACHILLI, Rosane G.; SCAVASSA, Ailton J.; SPIRI, Wilza. C. A identidade do agente comunitário de saúde: uma abordagem fenomenológica. Ciência \& Saúde Coletiva, Rio de Janeiro, v. 13, n. 1, 2008. Disponível em: $<$ www.scielo.br/pdf/csc/v13nl/09.pdf $>$. Acesso em: 10 jun 2008.

BARBOSA, Regina H. S. Análise do trabalho do ACS na perspectiva de gênero. In: DAVID, Helena M.S.L. et al. Abordagem interdisciplinar das novas condições e processos de trabalho em saúde: o caso dos agentes comunitários de saúde. Relatório de Pesquisa. Universidade do Estado do Rio de Janeiro, dez. 2009.

BORNSTEIN, Vera J. O agente comunitário de saúde na mediação de saberes. 2007. $243 \mathrm{f}$. Tese (Doutorado em Saúde Pública) - Escola Nacional de Saúde Pública Sergio Arouca, Fundação Oswaldo Cruz, Rio de Janeiro, 2007.

BORNSTEIN, Vera J.; STOTZ, Eduardo N. Concepts involved in the training and work processes of community healthcare agents: a bibliographical review. Ciência \& Saúde Coletiva, Rio de Janeiro, v. 13, n. 1, 2008. Disponível em: <www.scielosp.org/pdf/csc/ v13nl/28.pdf $>$. Acesso em: 08 jun. 2008.

BRASIL. Emenda constitucional n. ${ }^{\circ} 51$, de 14 de fevereiro de 2006. Acrescenta os $\S \S 4^{\circ}$, $5^{\circ}$ e $6^{\circ}$ ao art. 198 da Constituição Federal. Brasília, DF, 2006a. Disponível em: $<$ www.planalto.gov.br/ccivil_03/constituicao/ emendas/emc/emc51.htm>. Acesso em: 06 nov. 2009.

Ministério da Saúde. Departamento de Atenção Básica. Guia prático do Programa Saúde da Família. Brasília, DF, 2000.

Lei n. ${ }^{\circ}$ 10.507, de 10 de julho de 2002. Cria a profissão de agente comunitário de saúde e dá outras providências. Brasília, DF, 2002. Disponível em: <http://dtr2004. saude.gov.br/dab/docs/legislacao/lei10507_ 10_07_02.pdf>. Acesso em 13 out. 2008.

Lei n. ${ }^{\circ} 11.350$, de 5 de outubro de 2006. Regulamenta o $\S 5^{\circ}$ do art. 198 da Constituição, dispõe sobre o aproveitamento de pessoal amparado pelo parágrafo único do art. $2^{\circ}$ da emenda constitucional n. ${ }^{\circ} 51$, de 14 fev. 2006, e dá outras providências. Brasília, DF, 2006b. Disponível em: $<$ www.planalto.gov.br/ccivil_03/_Ato2004 -2006/2006/Lei/L11350.htm>. Acesso em: 06 nov. 2009.

Portaria n. ${ }^{\circ} 1.886 / \mathrm{GM}$, de $18 \mathrm{de}$ dezembro de 1997. Aprova as normas e diretrizes do programa de agentes comunitários de saúde e do Programa de Saúde da 
Família. Diário Oficial [da] República Federativa do Brasil, Brasília, DF, p. 11-13, 22 dez. 1997. Disponível em: <www.saude.sc. gov.br/PSF/PORTARIAS/Portaria\% 20n 1886 \%20-\%20original \% 2018dez1997.doc $>$. Acesso em: 23 ago. 2008.

Projeto de Expansão e Consolidação do Saúde da Família (Proesf). Brasília, DF: MS, 2003.

- Ministério da Educação. Referencial curricular para curso técnico de agente comunitário de saúde: área profissional saúde. Brasília, DF, 2004. Disponível em: <http://iah.iec.pa.gov.br/iah/fulltext/pc/ monografias/ms/sp/referencial_Curricular_ ACS.pdf>. Acesso em 17 nov. 2008.

CIAVATTA, Maria. O trabalho como princípio educativo na sociedade contemporânea. Síntese do texto discutido com os participantes do Seminário Nacional de Formação - MST, Escola Nacional Florestan Fernandes, mar. 2005. Guararema, SP, 2005. Disponível em: $<$ www.pedagogia.seed.pr.gov.br/arquivos/ File/Docs\% 20CGE/trabahocomoprincipio edtucativo.pdf $>$. Acesso em: 14 jan. 2010.

CONFERÊNCIA INTERNACIONAL SOBRE CUIDADOS PRIMÁRIOS À SAÚDE. Declaração de Alma-Ata. Alma-Ata, 1978. Disponível em: <www.opas.org.br/coletiva/uploadArq/ Alma-Ata.pdf>. Acesso em: 06 out. 2009.

DAVID, Helena M. S. L. Religiosidade e cotidiano das agentes comunitárias de saúde: repensando a educação em saúde junto às classes populares. 2001. 320 f. Tese (Doutorado em Saúde Pública) - Escola Nacional de Saúde Pública Sérgio Arouca, Fundação Oswaldo Cruz, Rio de Janeiro, 2001.

FREIRE, Paulo. Pedagogia do oprimido. Rio de Janeiro: Paz e Terra, 2005. 213 p.

FRIGOTTO, Gaudêncio. Educação e Trabalho: bases para debater a Educação Profissional Emancipadora. Revista Perspectiva, Florianópolis, v. 19, n. 1, p. 71-87, jan./jun. 2001. Disponível em: <www.perspectiva.ufsc.br/ perspectiva_2001_01/04_frigotto.pdf $>$. Acesso em: 23 out. 2008.
GORZ, André. Metamorfoses do trabalho: crítica da razão econômica. 2. ed. São Paulo: Annablume, 2007. 248 p.

JUNGES, José R.; MAZARI, Carla K.; SELLI, Lucilda. Agentes comunitários de saúde: perfil e formação. Ciência \& Saúde Coletiva, 2008. Disponível em: <www.abrasco.org.br/ cienciaesaudecoletiva/artigos/artigo_int.php? id_artigo $=3230>$. Acesso em: 15 jul 2009.

KLUTHCOVSKY, Ana C. G. C.; TAKAYANAGUI, Angela M. M. O trabalho do agente comunitário de saúde. Revista Brasileira de Medicina de Família e Comunidade, Rio de Janeiro, v. 2, n. 5, p. 23-29, abr./jun. 2006.

MACIEL, Fabrício. Todo trabalho é digno?: um ensaio sobre moralidade e reconhecimento na modernidade periférica. In: SOUZA, J. A invisibilidade da desigualdade brasileira. Belo Horizonte: Ed. UFMG. 2006.

MENDONÇA, Maria Helena M. Profissionalização e regulamentação da atividade do agente comunitário de saúde no contexto da reforma sanitária. Revista Trabalho, Educação e Saúde, Rio de Janeiro, v. 2, n. 2, p. 353365,2004

MOROSINI, Márcia V. G. C. A politica de formação dos agentes comunitários de saúde: memória de uma formulação em disputa nos anos 2003-2005. 2009. 224 f. Dissertação (Mestrado em Saúde Coletiva) - Instituto de Medicina Social, Universidade do Estado do Rio de Janeiro, Rio de Janeiro, 2009.

MOROSINI, Márcia V. G. C.; CORBO, Ana. D.; GUIMARÃES, Cátia C. O agente comunitário de saúde no âmbito das políticas voltadas para a atenção básica: concepções do trabalho e da formação profissional. Revista Trabalho, Educação e Saúde, Rio de Janeiro, v. 5, n. 2, p. 261-280, 2007. Disponível em: <www.revista.epsjv.fiocruz.br// include/mostrarpdf.cfm?Num $=170>$. Acesso em: 25 nov. 2009.

MOURA, Rita C. S. O programa de agentes comunitários de saúde adaptado à cidade do Rio de Janeiro: uma análise de suas con- 
cepções. 2009. 108 f. Dissertação (Mestrado em Saúde Coletiva) - Instituto de Medicina Social, Universidade do Estado do Rio de Janeiro, Rio de Janeiro, 2009.

NUNES, Mônica O. et al. O agente comunitário de saúde: construção desse personagem híbrido e polifônico. Cadernos de Saúde Pública, Rio de Janeiro, v. 18, n. 6, p. 16391646, 2002.

RIGOTTI, José I. R. A transição da escolaridade no Brasil. Revista Brasileira de Estudos de População, v. 18, n. 1/2, jan./dez. 2001.

SAVIANI, Demerval. O trabalho como principio educativo frente às novas tecnologias. Disponível em: <www.diaadia.pr.gov.br/nre/ cornelioprocopio/arquivos/File/Ensinomedio blocos/Encontro3Otrabalhocomoprincipio educativo.pdf $>$. Acesso em 14 jan. 2010.
SCHWARTZ, Yves. Trabalho e valor: tempo social. Revista Sociologia USP, São Paulo, v. 8, n. 2, p. 147-158, 1996.

SILVA, Joana A.; DALMASO, Ana. Sílvia W. Agente comunitário de saúde: o ser, o saber, o fazer. Rio de Janeiro: Ed. Fiocruz, 2002. 240p.

STOTZ, Eduardo N. O capitalismo ainda é aquele, mas para onde vai? Análise conjuntural. Nós da Rede: Boletim da Rede de Educação Popular e Saúde, n. ${ }^{\circ}$ 8, jan. 2009, p. 10 (on line). Disponível em: <www.edpopsaude. net/edpopsaude/Boletim_8_files/boletim_ 2009.pdf.> Acesso em: 10 jan. 2010.

Recebido em 01/02/2010

Aprovado em 31/03/2010 